\title{
Effect of Commercial Slow-Release Urea Product on in Vitro Rumen Fermentation and Ruminal Microbial Community Using RUSITEC Technique
}

\section{Yongmei Guo}

Inner Mongolia Agriculture University: Inner Mongolia Agricultural University

Ling Xiao

hangzhou king technina feed co Itd

Long Jin

agriculture and agri-food canada

\section{Sumei Yan}

Inner Mongolia Agriculture University: Inner Mongolia Agricultural University

Dongyan Niu

university of calgary

Wenzhu Yang ( $\nabla$ wenzhu.yang@agr.gc.ca )

Research Centre, Agriculture and Agri-food Canada, Lethbridge, Alberta, Canada

\section{Research Article}

Keywords: Slow-release urea, Dairy cow diet, Fermentation characteristics, Artificial rumen system

Posted Date: October 29th, 2021

DOI: https://doi.org/10.21203/rs.3.rs-1017842/v1

License: (1) This work is licensed under a Creative Commons Attribution 4.0 International License.

Read Full License 


\section{Abstract}

\section{Background}

The objectives of this study were to determine the effect of commercial slow-release urea (SRU) on in vitro fermentation characteristics, nutrient digestibility, gas production, microbial protein synthesis and bacterial community using rumen simulation technique (RUSITEC). The experiment was a completely randomized design with four treatments and four replications of each treatment. Treatments were: control diet (no SRU addition), control diet plus $0.28 \%$ SRU (U28), or plus $0.56 \%$ SRU (U56), and control diet that was modified for substituting with $0.35 \%$ SRU for equavelant soybean protein (MU35; dry matter [DM] basis). The experiment consisted of 8 days of adaptation and 7 days of data and sample collection. Rumen inoculum was obtained from three ruminally fistulated Angus cows fed the same diet to the substrate incubated.

\section{Results}

Digestibility of DM, organic matter (OM), crude protein (CP), fibre and starch was not affected, but daily production of gas $(P<0.07)$ and methane $(P<0.05)$ was quadratically changed with increasing SRU supplementation. The increase of SRU addition did not affect fermentation $\mathrm{pH}$ and total volatile fatty acid (VFA) production, whereas linearly $(P<0.01)$ decreased proportion of propionate, and linearly $(P<$ $0.01)$ increased acetate to propionate ratio and ammonia nitrogen $(\mathrm{N})$ concentration. The microbial $\mathrm{N}$ efficiency also linearly $(P<0.03)$ improved with increasing supplementation of SRU. In comparison with control diet, the dietary substitution of SRU for part of soybean meal increased $(P<0.05)$ the digestibility of $\mathrm{DM}, \mathrm{OM}$ and $\mathrm{CP}$ and decreased $(P<0.02)$ the total gas production. The total VFA production and acetate to propionate ratio did not differ between control and MU35, whereas the proportion of butyrate was lower $(P<0.05)$ and that of branched-chain VFA was greater $(P<0.05)$ with MU35 than control diet. Total and liquid-associated microbial $\mathrm{N}$ production as well as ammonia $\mathrm{N}$ concentration were greater $(P<$ 0.03) with MU35 than control diet. Observed OTUs, Shannon diversity index, and beta diversity of the microbial community did not differ among treatments. Taxonomic analysis revealed no effect of adding $\mathrm{SRU}$ on the relative abundance of bacteria at the phylum level, while at the genus level, the impact of SRU addition on microbial community was greater with MU35 either for liquid associate bacteria or feed particle-associated bacteria.

\section{Conclusions}

Supplementation of a dairy cow diet with SRU showed potential of increase in ammonia N concentration and microbial protein production, and change fermentation pattern to more acetate production. Adding $\mathrm{SRU}$ in dairy cow diet also showed beneficial effect on improving digestibility of OM and fibre. The results suggest that SRU can partially substitute soybean meal in dairy cow diet to increase microbial protein production without impairing rumen fermentation. 


\section{Background}

Dietary protein plays an important role in ruminant nutrition for providing amino acids and the nitrogen $(\mathrm{N})$ source for microbial protein production in rumen. However, the dietary protein is an expensive feed ingredient, and thus a strategy to reduce feed cost without negatively impact animal production needs to be considered. Non-protein nitrogen (NPN), such as urea, is commonly used as a replacement of feed protein in ruminant diets due to its low cost [1]. Whereas, the urea could be poorly utilized as a $\mathrm{N}$ source for microbial protein synthesis because it is rapidly hydrolyzed by rumen bacterial ureases to ammonia, and it often exceeds the use capacity by rumen bacteria with the surplus being absorbed through the rumen wall into the blood [2]. Synchronizing $\mathrm{N}$ supply with microbial requirements in the rumen is an important nutritional strategy to improve energy and $\mathrm{N}$ utilization. A way to improve the $\mathrm{N}$

synchronization with microbial need is to slow down the release rate of urea into ammonia by coating the granules with substrates that is able to protect them from rapid degradation [3]. For achieving this goal, numbers of rumen protected urea products, such as oil-coated, calcium-bound, polymer-coated sources of urea have been developed [4]. Although numerous studies have tested the effectiveness of slow-release urea (SRU) product in ruminant diets to improve ammonia assimilation in the rumen [5-8], the results were substantially variable. The behavior of SRU likely depends on the rate of urea release, amount of inclusion, type of diets, the nature of the rumen microbiota, and host traits, such as absorption of ruminal $\mathrm{NH}_{3}$ and liquid and solid passage rates.

Although the use of SRU is primarily to provide a steady supply of $\mathrm{N}$ to synchronize energy availability for supporting the microbial protein synthesis, adding the SRU in the ruminant diets appeared not only for providing $\mathrm{N}$ source in the rumen. Supplementation of SRU also affected rumen microbial diversity and community composition. Alipour et al. [9] suggested an improvement of fibrolytic bacterial activity by adding SRU in a high-grain diet. Ferme et al. [10] reported an inhibition of major ammonia producing bacteria (e.g., Prevotella ruminantium and Prevotella bryantii) and thus a reduction in $\mathrm{NH}_{3}-\mathrm{N}$ concentration in continuous culture. Moreover, several studies reported that the lower dose of SRU actually resulted in better growth performance of yak fed diet supplemented with $1 \%$ than with $2 \%$ of SRU [8] or the higher fibre digestibility of a high-grain diet with 0.5 and $1 \%$ SRU than $1.75 \%$ SRU supplementation in Rusitec [9]. Whereas, Tedeschi et al. [5] found no improvement in growth performance when urea was substituted by a SRU at levels normally found in feedlot cattle diets. The discrepancy in results among studies suggest that the rumen microbial community and profiles should be studied to elucidate mechanisms involved in the effects of SRU addition in dairy cow diets, because the understanding of the effect of SRU on rumen microbiota is scarce.

In addition, the soybean meal (SBM) is one of the commonly used as a prominent source of protein in dairy cow diets. It offers a good balance and availability of amino acids, and its amino acid profile is similar with that of ruminal bacteria. Due to the fluctuation in price of SBM and persistent increase in recent years, searching in alternatives of SBM comes to an inevitable trend to reduce production costs, maintain or maximize cattle performance and decrease greenhouse gas emission resulting from the excretion of $\mathrm{N}$ [11]. Therefore, the use of NPN replacement is attractive in cattle diets because of its low 
cost $[7,12]$. However, the consequences of replacing sources of true protein with SRU in diets remain unclear. We hypothesized that rumen fermentation characteristics and microbial community composition would be affected with increasing addition of SRU or partly substitution of SBM with SRU in dairy cow diet because of its improvement of microbial $\mathrm{N}$ utilization through slow ammonia release and higher microbial synthetic efficiency in the rumen. The objectives of this study were to evaluate the effects of 1) increasing dosages of SRU supplementation and 2) substituting with $0.35 \%$ SRU for equavelant soybean protein in a forage-based diet on rumen fermentation, nutrient digestibility, microbial protein synthesis and microbial community in Rusitec.

\section{Methods}

\section{Experimental design}

The experiment was a completely randomized design with four treatments assigned to sixteen fermentation vessels in two eight-vessel RUSITEC apparatus with four replications for each treatment. The treatments were control diet (no SRU), control plus $0.28 \%$ SRU (U28), control plus $0.56 \%$ SRU (U56), and control diet was modified for substituting with $0.35 \%$ SRU for equavelant soybean protein. The diets were formulated to be isoenergetic, but protein concentration of U28 and U56 increased due to SRU addition and isonitrogenic between control and U35 diets (Table 1). The SRU product was provided by King Techina Feed Co., Ltd. (Hangzhou, China) and it was prepared based on a matrix of urea pills (87\%) and palm oil and sodium carboxymethyl cellulose (13\%). The release rate of SRU was $52.1 \%$ at $6 \mathrm{~h}$ and $71.3 \%$ at $12 \mathrm{~h}$ of incubation in artificial rumen fluid. The experiment was conducted as one period consisting of 15 days, including 8 days of adaptation and followed by 7 days for sample and data collection. The basal diet was prepared in the form of total mixed ration (TMR), and ground through a 4 $\mathrm{mm}$-sieve. Approximately $10 \mathrm{~g}$ (dry matter, DM) of the basal diet was weighed into nylon bags $(10 \times 20$ $\mathrm{cm}$; pore size of $50 \mu \mathrm{m}$, Ankom Technology Corp., Macedon, NY, USA), and SRU was added to bags at the desired concentration followed by manual mix. 
Table 1

Ingredient and chemical composition of experimental diets

\section{Diets}

\begin{tabular}{lllll|}
\hline Item & Control & U28 & U56 & MU35 \\
\hline Ingredient, \% & & & & \\
\hline Corn silage & 27.1 & 27.1 & 27.1 & 27.1 \\
\hline Alfalfa hay & 11.4 & 11.4 & 11.4 & 11.4 \\
\hline Ort hay & 7.0 & 7.0 & 7.0 & 7.0 \\
\hline Steam flaked corn & 24.4 & 24.4 & 24.4 & 26.1 \\
\hline Soybean meal, 46\% & 10.6 & 10.6 & 10.6 & 8.9 \\
\hline Canola meal & 2.8 & 2.8 & 2.8 & 2.8 \\
\hline Extrude soybean & 3.4 & 3.4 & 3.4 & 3.4 \\
\hline DDGS ${ }^{1}$ & 2.1 & 2.1 & 2.1 & 2.1 \\
\hline Dried beet pulp & 6.84 & 6.84 & 6.84 & 6.84 \\
\hline Mineral and vitamin & 1.82 & 1.82 & 1.82 & 1.82 \\
\hline Mycotoxin binder & 0.08 & 0.08 & 0.08 & 0.08 \\
\hline Soda & 0.57 & 0.57 & 0.57 & 0.57 \\
\hline Saturated fat & 1.90 & 1.90 & 1.90 & 1.90 \\
\hline Slow-released urea ${ }^{2}$ & 0 & 0.28 & 0.56 & 0.35 \\
\hline Chemical composition, \% of DM & 16.2 & 16.9 & 17.7 & 16.2 \\
\hline DM & 30.4 & 30.4 & 30.4 & 30.5 \\
\hline OM & 19.0 & 19.0 & 19.0 & 19.0 \\
\hline CP & 92.4 & 92.4 & 92.4 & 92.5 \\
\hline ADF & & & & \\
\hline
\end{tabular}

${ }^{1}$ DDGS $=$ Distillers dried grains with solubles.

${ }^{2}$ The product contains $13 \%$ of coating materials of palm oil and sodium carboxymethyl cellulose and $87 \%$ of urea.

${ }^{3} \mathrm{NE}_{\mathrm{L}}=$ Net energy for lactation. 


\begin{tabular}{|lllll|}
\hline \multicolumn{4}{|c|}{ Diets } \\
\hline Starch & 27.1 & 27.1 & 27.1 & 28.2 \\
\hline $\mathrm{NE}_{\mathrm{L}}{ }^{3}, \mathrm{Mcal} / \mathrm{kg}$ & 1.71 & 1.71 & 1.71 & 1.71 \\
\hline${ }^{1} \mathrm{DDGS}=$ Distillers dried grains with solubles. & & & & \\
\hline $\begin{array}{l}{ }^{2} \mathrm{The} \text { product contains 13\% of coating materials of palm oil and sodium carboxymethyl cellulose and } \\
87 \% \text { of urea. }\end{array}$ & & & & \\
\hline${ }^{3} \mathrm{NE}_{\mathrm{L}}=$ Net energy for lactation. & & & & \\
\hline
\end{tabular}

\section{Inoculum donor}

The experimental protocols were reviewed and approved by the Lethbridge Research and Development Centre Animal Care Committee, and cattle were handled in accordance with the guidelines of the Canadian Council on Animal Care [13].

Three ruminally cannulated Angus cross cows (averaging $668 \pm 55.1 \mathrm{~kg}$ body weight) that fed a TMR similar to the diet used in Rusitec (containing 35\% corn silage, $10 \%$ mixed hay, and 55\% corn-based concentrate mix, DM basis) were used as inoculum donor. Two hours after morning feeding, solid rumen digesta and rumen liquid were collected from four locations within the rumen of each cow via rumen cannula. Contents were immediately pooled over in equal amount ( $4 \mathrm{~L}$ per cattle), filtered through four layers of cheesecloth into an insulated thermos and transported to the laboratory directly. Rumen liquid was well mixed, $\mathrm{pH}$ recorded and kept at $39^{\circ} \mathrm{C}$ in a water bath prior to introduction into fermenters.

\section{Experimental procedure}

Two RUSITEC apparatuses were used in this study with each equipped with eight $920 \mathrm{~mL}$ volume anaerobic fermenters, as described in previous study [14]. The fermenters were randomly chosen, and each fermenter was outfitted with a port for buffer input, and a port for effluent output. To begin the experiment, each fermenter was filled with $200 \mathrm{~mL}$ of McDougalls buffer $(\mathrm{pH}=8.2)$ [15], $700 \mathrm{~mL}$ of strained rumen fluid, and two pre-labeled nylon bags with one containing $20 \mathrm{~g}$ of mixed solid rumen digesta from four donor cattle and one containing diet substrate with or without SRU addition. The fermenters were incubated in a water bath at $39^{\circ} \mathrm{C}$. After $24 \mathrm{~h}$ of incubation, the nylon bag containing solid rumen digesta was removed from fermenter and replaced by one new bag with substrate with or without SRU. Thereafter, one diet bag was replaced daily in the morning so that each bag will remain in the fermenter for $48 \mathrm{~h}$ except the last day when one bag in each vessel was removed after $24 \mathrm{~h}$. Artificial saliva [15] was infused into the fermenter continuously by a peristaltic pump set (Model ISM 932D, Ismatec, Index Health and science $\mathrm{GmbH}$, Wertheim, Germany) at a dilution rate of $2.9 \% / \mathrm{h}$. On $\mathrm{d} 8$, the chemical composition of the artificial saliva was modified by mixing ammonium sulfate enriched with ${ }^{15} \mathrm{~N}\left(\left({ }^{15} \mathrm{NH}_{4}\right)_{2} \mathrm{SO}_{4}\right.$; Sigma Chemical Co., St. Louis, MO, USA; minimum ${ }^{15} \mathrm{~N}$ enrichment $\left.1 \mathrm{~g} / \mathrm{L}\right)$ into the 
infused buffer solution to label bacteria. Daily effluent was collected into a $2 \mathrm{~L}$-volumetric flask, and gas was collected in a 2 L-bag (CurityR; Conviden Ltd., Mansfield, MA, USA). The effluent in each flask was preserved with $3 \mathrm{~mL}$ of a sodium azide solution to stop the microbial activity during the sample collection period.

\section{Nutrient disappearance}

Nutrient disappearance including DM, organic matter (OM), crude protein (CP), acid detergent fibre (ADF), neutral detergent fibre (NDF) and starch was measured from $d 9$ to 13 of the sampling period [16]. Feedbags were removed from fermenters after 48-h incubation and then hand-washed under running water until the water runoff was clear. Afterwards, feedbags were dried in oven at $55^{\circ} \mathrm{C}$ for $48 \mathrm{~h}$ for DM disappearance determination [17]. Feed residues from the same fermenter and collected over 5 days were pooled, and grounded through a $1 \mathrm{~mm}$-screen using a Wiley mill (standard model 4 Arthur Thomas Co., Philadelphia, PA, USA) for chemical analysis. Part of grounded feed residue was further ground with a ball mill (Mixer Mill MM2000; Retsch, Haan, Germany) for total N and starch analysis. Ash content was analyzed by combustion samples at $550^{\circ} \mathrm{C}$ for $5 \mathrm{~h}$ (method 942.05) [17], and OM content was calculated as 100 minus the ash content. The NDF and ADF were determined on a VELP Fiber Digestion System (VELP Scientifica, Burlington, ON, Canada) using the method as described by Van Soest et al. [18] and AOAC (method 973.18) [17], respectively. Total $N$ was determined using a combustion analyzer (NA 2100, Carlo Erba Instruments, Milan, Italy) according to Smith and Tabatabai [19], and CP was calculated as total $N \times 6.25$. Starch was determined by enzymatic hydrolysis of a-linked glucose polymers [20]. Disappearance of $D M, O M, C P, N D F, A D F$, and starch was calculated as the differences between the amount of individual component in substrates before incubation and that in residues after $48 \mathrm{~h}$ of incubation. The chemical analysis was conducted in duplicate, and repeated if the CV for the replicate analysis was more than $5 \%$.

\section{Fermentation parameters, gas and methane production}

Fermenter pH using a pH meter (Orion model 260A, Fisher Scientific, Toronto, Canada) and the volume of daily effluent were measured daily at the time of feedbag exchange. From $d 9$ through $d 13$, effluent (5 $\mathrm{mL}$ ) was preserved with $1 \mathrm{~mL}$ of $25 \%$ metaphosphoric acid (w/v) for analysis of volatile fatty acid (VFA). Another subsample of effluent $(5 \mathrm{~mL})$ was preserved with $1 \mathrm{~mL}$ of $1 \% \mathrm{H}_{2} \mathrm{SO}_{4}$ (vol/vol) for ammonia $\mathrm{N}$ $\left(\mathrm{NH}_{3}-\mathrm{N}\right)$ analysis. All samples were stored in frozen at $-20^{\circ} \mathrm{C}$ until analysis. Concentration of VFA was quantified using a gas chromatograph (model 5890, Hewlett-Packard Lab, Palo Alto, CA, USA) equipped with a capillary column $(30 \mathrm{~m} \times 0.32 \mathrm{~mm}$ i.d., $1-\mu \mathrm{m}$ phase thickness, Zebron ZB-FAAP, Phenomenex, Torrance, CA, USA) and flame ionization detection, with crotonic acid (trans-2-butenoic acid) used as internal standard. The concentrations $(\mathrm{mmol} / \mathrm{L}$ ) of total VFA were calibrated based on daily effluent

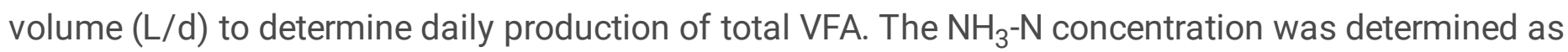
described by Rhine et al. [21]. For protozoa enumeration, $1 \mathrm{~mL}$ of liquid was gently squeezed from the 48$\mathrm{h}$ incubated feed bag and transferred to a screw-cap vial containing $1 \mathrm{~mL}$ of methyl green-formalin-saline solution on $\mathrm{d} 11$ to 13 . The samples were stored at room temperature and prevented from light until 
counting by light microscopy with a Levy-Hausser counting chamber (Hausser Scientific, Horsham, PA, USA).

Total gas production was measured daily using a gas meter (Model DM3A, Alexander-Wright, London, UK). From d 9 to 13 , a volume of $20 \mathrm{~mL}$ gas was collected from each gas collection bag using a syringe into evacuated $6.8 \mathrm{~mL}$-exetainers (Labco Ltd., Wycombe, Bucks, UK). Methane concentration were determined using a Varian 4900 gas chromatograph equipped with a GS-Carbon PLOT $30 \mathrm{~m} \times 0.32 \mathrm{~mm} \times$ $3 \mu \mathrm{m}$ column and thermal conductivity detector (Agilent Technologies Canada Inc., Mississauga, ON, Canada) at an isothermal oven temperature of $35^{\circ} \mathrm{C}$, with helium as the carrier gas $(27 \mathrm{~cm} / \mathrm{s})$.

\section{Microbial protein synthesis}

Microbial protein synthesis was estimated as the sum of microbial biomass in the form of liquidassociated bacteria (LAB), feed particle-associated (FPA) and feed particle-bound (FPB) bacterial fractions. On d 14 and 15 , the daily total effluent for each fermenter was measured and a subsample (250 $\mathrm{mL}$ ) was centrifuged $\left(20,000 \times \mathrm{g}, 30 \mathrm{~min}, 4^{\circ} \mathrm{C}\right)$ for isolation of $L A B$. The resulting pellets were washed with PBS and centrifuged $\left(20,000 \times \mathrm{g}, 30 \mathrm{~min}, 4^{\circ} \mathrm{C}\right)$ three times prior to suspension in distilled water, and stored in frozen. at the meantime, feedbags followed by $48 \mathrm{~h}$ of incubation, were put in a specific plastic bag with $20 \mathrm{~mL}$ of McDougall's buffer and processed for $1 \mathrm{~min}$ in a Stomacher 400 Laboratory Blender (Seward Medical Ltd, London, UK). Feed residues were hand washed twice with $10 \mathrm{~mL}$ of McDougall's buffer. All processed liquid was collected in centrifuge tubes, centrifuged $\left(500 \times \mathrm{g}, 10 \mathrm{~min}, 4^{\circ} \mathrm{C}\right)$ to remove large feed particles, and the supernatant was centrifuged $\left(20,000 \times \mathrm{g}, 30 \mathrm{~min}, 4^{\circ} \mathrm{C}\right)$ following the same procedure as for the LAB for obtaining FPA pellet. Washed feed residues (FPB fraction) were dried at $55^{\circ} \mathrm{C}$ for $48 \mathrm{~h}$ and weighed for amount of solid DM determination. The $L A B$ and FPA pellets were freeze-dried and the samples (LAB, FPA and FPB) were ball ground (MM400; Retsch Inc., Newtown, PA, USA) for analysis of $\mathrm{N}$ and ${ }^{15} \mathrm{~N}$ by combustion analysis coupled to a mass spectrometer (NA1500, Carlo Erba Instruments, Milan, Italy).

\section{Microbial community}

Each of FPA and LAB sample were pooled from d 14 and 15 collection, and total microbial DNA was extracted using the Qiagen DNeasy PowerLyzer PowerSoil kit (Qiagen Inc., Mississauga, ON, Canada) according to manufacturer's instructions. The concentration of DNA was measured using the Qubit dsDNA BR Assay Kit (Thermo Fisher Scientific Inc., Waltham, MA, USA) with a Qubit 2.0 Fluorometer (Thermo Fisher Scientific Inc., Waltham, MA, USA). Negative extraction controls were included in duplicate for control of extraction contamination. The extracted DNA was stored at $-20^{\circ} \mathrm{C}$ until sequencing.

All PCR amplification and sequencing steps were carried out at Genome Quebec (Montreal, QC, Canada). Libraries of 16S rRNA gene sequence were generated using a two-step PCR protocol. The V4 region of the 16S rRNA gene was amplified using the universal bacterial and archaeal primers 515-F (GTGYCAGCMGCCGCGGTAA) and 806-R (GGACTACNVGGGTWTCTAAT) in the first step of PCR [22]. A unique 10-bp barcode and Illumina (IIlumina, San Diego, CA, USA) adapter sequences were added at the 5 ' end of each amplicon in the second PCR step. The 16S rRNA gene amplicons were quantified using a 
Quant-iT PicoGreen dsDNA assay kit (Invitrogen, Burlington, ON, Canada), pooled in equimolar ratios, and then purified with AMPure XP beads (Beckman Coulter, Mississauga, ON, Canada). Sequencing of $16 \mathrm{~S}$ rRNA gene amplicons was carried out according to manufacturer's instructions using an Illumina MiSeq $(2 \times 250)$ and the MiSeq Reagent Kit v2 (500 cycles; Illumina).

Sequencing quality was checked with FastQC 0.11.5 and MultiQC 1.0 [23]. De-noised reads were used to construct amplicon sequence variants (SVs) using QIIME2 [24]. Analysis of 16S rRNA gene sequences was processed and analyzed within the QIIME2 and the R package DADA2 (Version 1.4). Sequences were then assigned to operational taxonomic units (OTUs) at $97 \%$ similarity using an open-reference OTU picking method and the Greengenes database v13_8 (). In this method, sequences that were less than $97 \%$ similar to those in the Greengenes database were clustered into OTUs using the de novo approach and USEARCH. The Shannon diversity index and observed OTU were calculated in QIIME2 and Bray-Curtis dissimilarities were assessed using the $R$ packages vegan v. 2.4.4 [25] and phyloseq v. 1.20.0 [26]. Alpha diversity was estimated by observed OTUs and Shannon diversity index by using QIIME2. Beta diversity was performed to evaluate differences in overall bacterial communities by non-metric multidimensional scaling (NMDS), based on Bray-Curtis dissimilarities, using the vegan package of the R software suite. The significance of between-groups differentiation on Bray-Curtis dissimilarity was assessed by PERMANOVA using the adonis function of the $\mathrm{R}$ package vegan with 999 permutations. Differentially abundant OTUs between treated group and control group were identified with a threshold of $5 \%$ using DESeq2 [27].

\section{Statistical analysis}

Data were analyzed as repeated measures according to a completely randomized design using the MIXED procedure of SAS (Version 16.0.0, SAS Inst. Inc., Cary, NC, USA), with treatment as fixed effect, day of sampling as repeated measures, and fermenter and RUSITEC apparatus as random effect. For the repeated measures, various covariance structures were tested with the final structure chosen based on the minimum Akaike's information criteria value. The protozoa count data were normalized by $\log _{10}$ transformation prior to statistical analysis. Data were tested for normality of variance. Orthogonal polynomial contrasts were performed to test for linear and quadratic responses to SRU at different addition level (i.e., control, U28, U56). Contrasts were generated to compare the control and MU35. The differences were declared significant at $P \leq 0.05$ and trends at $0.05<P \leq 0.10$.

\section{Results}

\section{Effects of SRU on nutrient disappearance and gas production}

Disappearance of DM, OM, CP, NDF, ADF and starch was not affected by increasing the SRU supplementation in the diets (Table 2). However, the disappearance of DM $(P<0.01), \mathrm{OM}(P<0.03)$ and $\mathrm{CP}(P<0.04)$ was greater with MU35 than control diets. Gas production $(\mathrm{L} / \mathrm{d})$ tended $(P<0.07)$ to be 
quadratically changed with increasing SRU supplementation, and it was lower $(P<0.04)$ with MU35 than control. Increasing dietary SRU addition quadratically changed methane production, either expressed as mg CH $4 / \mathrm{d}(P<0.05)$ or $\mathrm{mg} \mathrm{CH}_{4} / \mathrm{g}$ digested DM $(P<0.08)$, which did not differ between control and MU35 diets.

Table 2

Effect of slow-release urea (SRU) supplementation on nutrient disappearances and gas production in RUSITEC

\begin{tabular}{|c|c|c|c|c|c|c|c|c|}
\hline \multirow[b]{2}{*}{ Item } & \multicolumn{5}{|c|}{ Treatment $^{1}$} & \multicolumn{3}{|l|}{$P<2$} \\
\hline & Control & U28 & U56 & MU35 & SEM & L & Q & C vs MU35 \\
\hline \multicolumn{9}{|l|}{ Digestibility, \% } \\
\hline DM & 74.1 & 74.9 & 74.9 & 78.5 & 0.96 & 0.51 & 0.66 & 0.01 \\
\hline $\mathrm{OM}$ & 74.6 & 74.6 & 74.1 & 78.9 & 1.03 & 0.74 & 0.86 & 0.03 \\
\hline $\mathrm{CP}$ & 75.3 & 77.8 & 76.2 & 81.2 & 1.58 & 0.73 & 0.35 & 0.04 \\
\hline NDF & 45.7 & 43.4 & 45.3 & 51.9 & 2.46 & 0.93 & 0.56 & 0.10 \\
\hline ADF & 41.7 & 41.0 & 39.1 & 47.2 & 2.44 & 0.49 & 0.88 & 0.12 \\
\hline Starch & 98.6 & 98.5 & 97.9 & 98.4 & 1.11 & 0.18 & 0.10 & 0.23 \\
\hline Gas production, L/d & 1.79 & 1.92 & 1.67 & 1.51 & 0.09 & 0.31 & 0.07 & 0.04 \\
\hline $\mathrm{CH}_{4}, \%$ of gas & 4.22 & 4.34 & 3.85 & 4.34 & 0.39 & 0.30 & 0.32 & 0.81 \\
\hline $\mathrm{CH}_{4}, \mathrm{mg} / \mathrm{d}$ & 45.43 & 55.27 & 43.18 & 44.92 & 4.25 & 0.70 & 0.05 & 0.86 \\
\hline $\mathrm{CH}_{4}, \mathrm{mg} / \mathrm{g}$ digested DM & 6.18 & 7.18 & 5.64 & 5.60 & 0.55 & 0.51 & 0.08 & 0.42 \\
\hline
\end{tabular}

${ }^{1}$ Control (no SRU), U28 = control plus $0.28 \%$ SRU, U $56=$ control plus $0.56 \%$ SRU, and MU35 = control diet was modified by partially replacing soybean protein with $0.35 \%$ SRU (DM basis);

${ }^{2} \mathrm{~L}, \mathrm{Q}=$ linear and quadratic effects of SRU (control, U28 and U56); C vs. MU35 = Contrast between Control and MU35.

\section{Effects of SRU on media pH and fermentation characteristics}

Fermenter pH was slightly lower $(P<0.03)$ with MU35 than control but it was not affected with increasing the dose of SRU (Table 3). Total VFA concentration or daily VFA production did not differ with increasing SRU supplementation, but it tended $(P<0.08)$ to be greater with MU35 than control diet. The increase of dietary SRU addition did not change molar proportion of acetate and butyrate, but quadratically changed the proportion of propionate $(P<0.01)$, branch-chained VFA $(P<0.01)$, valerate $(P<0.03)$ and caproate $(P$ $<0.01)$, and linearly $(P<0.01)$ increased the acetate to propionate ratio. There was lower $(P<0.04)$ 
proportion of butyrate and greater $(P<0.02)$ branch-chained VFA as well as greater $(P<0.02)$ acetate to propionate ratio with MU35 than control diet. Concentration of $\mathrm{NH}_{3}-\mathrm{N}$ either linearly $(P<0.01)$ increased with increasing SRU supplementation or it was greater $(P<0.01)$ with MU35 than control, whereas, protozoa counts in fermentation media did not differ among treatments.

Table 3

Effect of slow-release urea supplementation on fermentation $\mathrm{pH}$ and characteristics in Rusitec

\begin{tabular}{|c|c|c|c|c|c|c|c|c|}
\hline & Treatme & & & & & $P<2$ & & \\
\hline Item & Control & U28 & U56 & MU35 & SEM & L & Q & C vs MU35 \\
\hline $\mathrm{pH}$ & 6.81 & 6.80 & 6.80 & 6.77 & 0.01 & 0.25 & 0.47 & 0.03 \\
\hline $\mathrm{NH}_{3}-\mathrm{N}, \mathrm{mmol} / \mathrm{L}$ & 7.70 & 9.31 & 10.25 & 8.92 & 0.37 & 0.01 & 0.39 & 0.03 \\
\hline Total VFA, mmol/L & 78.5 & 80.2 & 79.3 & 85.7 & 2.86 & 0.21 & 0.65 & 0.08 \\
\hline \multicolumn{9}{|l|}{$\%$ of total VFA } \\
\hline Acetate (A) & 46.1 & 45.6 & 46.4 & 47.2 & 0.57 & 0.57 & 0.16 & 0.16 \\
\hline Propionate $(P)$ & 26.9 & 25.7 & 26.0 & 26.5 & 0.21 & 0.01 & 0.01 & 0.16 \\
\hline Butyrate & 14.9 & 15.5 & 15.2 & 14.2 & 0.24 & 0.38 & 0.13 & 0.04 \\
\hline BCVFA $^{3}$ & 2.8 & 3.2 & 2.9 & 3.2 & 0.09 & 0.87 & 0.01 & 0.02 \\
\hline Valerate & 7.8 & 8.4 & 7.9 & 7.4 & 0.25 & 0.63 & 0.03 & 0.22 \\
\hline Caproate & 1.3 & 1.6 & 1.5 & 1.4 & 0.05 & 0.02 & 0.01 & 0.08 \\
\hline$A: P$ & 1.69 & 1.77 & 1.78 & 1.77 & 0.03 & 0.01 & 0.24 & 0.02 \\
\hline Total VFA, $\mathrm{mmol} / \mathrm{d}$ & 50.5 & 53.1 & 52.0 & 55.9 & 2.05 & 0.13 & 0.18 & 0.06 \\
\hline Protozoa, $\times 10^{4} / \mathrm{mL}$ & 2.4 & 2.9 & 2.8 & 2.8 & 0.24 & 0.91 & 0.17 & 0.24 \\
\hline
\end{tabular}

${ }^{1}$ Control (no SRU), U28 = control plus $0.28 \%$ SRU, U $56=$ control plus $0.56 \%$ SRU, and MU35 = control diet was modified by partially replacing soybean protein with $0.35 \%$ SRU (DM basis);

${ }^{2} \mathrm{~L}, \mathrm{Q}=$ linear and quadratic effects of SRU (control, U28 and U56); C vs. MU35 = Contrast between Control and MU35.

${ }^{3} \mathrm{BCVFA}=$ Branched-chain volatile fatty acids (isobutyrate + isovalerate).

\section{Effects of SRU on microbial protein synthesis and microbial community}

Increasing SRU addition increased total microbial N production (quadratic, $P=0.05$ ), and the production of FPB (linear, $P<0.06)$, and linearly $(P<0.03)$ improved microbial $\mathrm{N}$ efficiency (Table 4$)$. There were 
greater $(P<0.03)$ production of total microbial $\mathrm{N}$ and trend $(P<0.08)$ of greater FPB production with MU35 than control diet, but the differences in LAB and FPA production, and the microbial N efficiency were not significant between MU35 and control group.

Table 4

Effect of slow-release urea (SRU) supplementation on microbial N production in Rusitec

\begin{tabular}{|c|c|c|c|c|c|c|c|c|}
\hline \multirow[b]{2}{*}{ Item } & \multicolumn{5}{|c|}{ Treatment $^{1}$} & \multicolumn{3}{|l|}{$P<2$} \\
\hline & Control & U28 & U56 & MU35 & SEM & L & Q & C vs MU35 \\
\hline \multicolumn{9}{|l|}{ Microbial $\mathrm{N}^{3}, \mathrm{mg} / \mathrm{d}$} \\
\hline Total & 78.9 & 84.5 & 83.8 & 83.4 & 1.88 & 0.14 & 0.05 & 0.03 \\
\hline LAB & 52.8 & 56.0 & 55.6 & 55.3 & 1.69 & 0.38 & 0.61 & 0.20 \\
\hline FPA & 15.0 & 15.7 & 14.9 & 15.3 & 0.81 & 0.97 & 0.47 & 0.79 \\
\hline FPB & 9.8 & 11.4 & 11.5 & 11.5 & 0.65 & 0.06 & 0.32 & 0.08 \\
\hline Efficiency of microbial $N^{4}$ & 9.5 & 11.5 & 11.7 & 10.2 & 0.30 & 0.03 & 0.12 & 0.17 \\
\hline \multicolumn{9}{|c|}{$\begin{array}{l}{ }^{1} \text { Control (no SRU), U28 = control plus } 0.28 \% \text { SRU, U56 = control plus } 0.56 \% \text { SRU, and MU35 = control } \\
\text { diet was modified by partially replacing soybean protein with } 0.35 \% \text { SRU (DM basis); }\end{array}$} \\
\hline \multicolumn{9}{|c|}{$\begin{array}{l}{ }^{2} \mathrm{~L}, \mathrm{Q}=\text { linear and quadratic effects of SRU (control, U28 and U56); C vs. MU35 = Contrast between } \\
\text { Control and MU35. }\end{array}$} \\
\hline \multicolumn{9}{|c|}{$\begin{array}{l}{ }^{3} \mathrm{LAB}=\text { liquid associate bacteria; FPA = feed particle-associated bacteria; FPB = feed particle-bound } \\
\text { bacteria. }\end{array}$} \\
\hline
\end{tabular}

The FPA and LAB samples were selected for high-throughput sequencing to assess the microbial community in the present study. Neither observed OTUs (Fig. 1A) nor Shannon diversity index (Fig. 1B) of FPA and LAB microbial community were affected by SRU supplementation. Similarly, the results of the NMDS indicated that there was no specific clustering of FPA and LAB microbial community either by adding SRU or by substituting SRU for SBM (Fig. 2). At the phylum level (Fig. 3), Bacteroidetes (38.6\%), Firmicutes (33.2\%), Spirochaetes (8.8\%), Proteobacteria (5.5\%), Fibrobacteres (4.1\%), Euryarchaeota $(4.0 \%)$, were the predominant ( $>94 \%$ of total), and they were overall not different among treatments except for Firmicutes. The RA of Firmicutes tended $(P=0.06)$ linearly increase with increasing SRU supplementation, and it was greater with MU35 than control in LAB samples. At the genus level (Fig. 4), Prevotella 1 (18.6\%), Treponema 2 (8.8\%), Rikenellaceae RC9 gut group (5.2\%), Fibrobacter $(4.1 \%)$, Lactobacillus (3.9\%), Megasphaera (3.4\%), Prevotella 7 (3.4\%), Bacteroidales bacterium Bact_22 (3.2\%) and Prevotellaceae YAB2003 group (2.5\%) were considered as the "core bacteria" in FPA and LAB. For FPA samples. The RA of Megasphaera linearly $(P<0.04)$ increased and the RA of Rikenellaceae RC9 gut group quadratically $(P<0.05)$ changed with increasing SRU addition in FPA sample. Prevotellaceae 
YAB2003 group in LAB samples tended $(P=0.06)$ linearly increased with increasing SRU

supplementation. In comparison with control, the MU35 had greater RA of Rikenellaceae RC9 gut group in LAB $(P=0.01)$ and Prevotellaceae YAB2003 group in FPA $(P=0.07)$.

The Log2 fold change analysis of the FPA samples found that several genera from phyla Firmicutes and Proteobacteria had 5\% more change (enhanced or reduced; $P_{\text {adj }}<0.05$ ) with SRU than the control (Fig. 5). The U28 group had more $\left(P_{\mathrm{adj}}<0.05\right)$ Family XIII AD3011 group and XBB1006 from phyla Firmicutes than control. The MU35 treatment enhanced $\left(P_{\mathrm{adj}}<0.05\right)$ the abundance of Roseburia from phyla Firmicutes, but reduced $\left(P_{\mathrm{adj}}<0.05\right)$ the abundance of Succinivibrio from phyla Proteobacteria as compared to the control. Similarly, genus of Family XIII AD3011 group from phyla Firmicutes was also susceptible to SRU supplementation in LAB samples; it was enhanced $\left(P_{\mathrm{adj}}<0.05\right)$ with U56 and MU35 diets compared with control and U28. Whereas, RA of Methanobrevibacter from phylum Euryarchaeota of LAB sample decreased $\left(P_{\mathrm{adj}}<0.05\right)$ with U56 and MU35. The MU35 versus control also had lower $\left(P_{\mathrm{adj}}<\right.$ $0.05)$ Eubacterium coprostanoligenes and Erysipelotrichaceae UCG-002, and higher $\left(P_{\mathrm{adj}}<0.05\right)$ Erysipelotrichaceae UCG-004.

\section{Discussion}

\section{Effects of SRU on nutrient disappearance and gas production}

The absent effect of increasing the dose of SRU in the diets from $0,0.28$ to $0.56 \%$ on nutrient digestibility is in agreement with some studies [7,28,29], but it is consistent with other studies $[9,30]$. With using continuous culture system, Xin et al. [7] found no differences in the nutrient digestibility of corn-based dairy cow diet supplemented with either feed grade urea or polyurethane coated urea. Gardinal et al. [29] reported that the nutrient digestibility in the total digestive tract was not affected by adding $2 \%$ polymercoated SRU in the diet of Nellore steers. In contrast, Alipour et al. [9] reported quadratically increased the digestibility of NDF and ADF of a high concentrate diet with increasing SRU dosages from $0,0.5,1.0$ to $1.75 \%$ in high concentrate diet in Rusitec. Another study has been demonstrated to increase total tract DM and CP digestibility when fed polymer-coated SRU to lactating dairy cows [6]. The theory behind using SRU is sustained release of urea within rumen to have a more consistent supply of ammonia $\mathrm{N}$ for increasing fibrolytic microbial activity and the microbial protein synthesis. It is clear that ammonia $\mathrm{N}$ concentration can influence fiber digestion in the rumen, but the literature has disagreements on the optimal ammonia $\mathrm{N}$ concentration for fiber digestion (19 and $23 \mathrm{mg} / \mathrm{dL}$ with Mehrez et al. [31]; 15 and 30 $\mathrm{mg} / \mathrm{dL}$ with Leng and Nolan [32]). Bryant reported that ammonia $\mathrm{N}$ concentration higher than $5 \mathrm{mg} / \mathrm{dl}$ is essential for the growth of cellulolytic bacteria [33]. Whereas, Alipour et al. [9] speculated that each diet has an optimal ammonia concentration because the microbial protein synthesis and ammonia use relate to the rate and extent of carbohydrate fermentation. In the present study, the lack of SRU effect (U28 and U56 diets) on the nutrient digestibility might be due to the low dose of SRU supplementation, and the differences in the ammonia $\mathrm{N}$ concentration was relatively small among treatments. Similarly, under the 
comparable experimental conditions to the current experiment (i.e., dairy diet, continuous culture and $0.6 \% \mathrm{SRU})$, Xin et al. [7] also did not observed the significant differences in the nutrient digestibility between feed grade urea and SRU diets.

The greater digestibility ( $+5.9 \%)$ of DM and OM with MU35 than control was resulted from increased the digestibility of CP (+7.8\%) and NDF (+13.6\%). The higher digestibility of DM, CP and NDF is consistent, respectively, with greater total VFA production, higher acetate to propionate ratio and increased microbial protein production with MU35 versus control. However, the improved nutrient digestibility with MU35 compared with control is a bit surprised, because the diet formulation and nutrient contents were overall similar between two treatments. Slightly higher steam-flaked corn at the expenses of SBM in MU35 may provide more digestible energy in the rumen and potentially increase microbial activity and microbial protein synthesis. This speculation can be explained by the higher CP degradability and numerically greater fibre digestibility.

The quadratic changes of gas production with increasing SRU supplementation may be explained by the linear increased $\mathrm{NH}_{3}-\mathrm{N}$ concentration, especially for U56 diet. Ammonia neutralizes the VFA and lower $\mathrm{CO}_{2}$ liberation from buffered fermentation media and, as a result, decrease gas production [34]. In comparison of MU35 with control, although more OM was fermented and greater VFA was produced, gas production $(\mathrm{L} / \mathrm{d})$ was lower. The lower total gas production along with the higher digestibility of OM with MU35 indicated an improved fermentation efficient. With in vitro rumen fermentation, truly digested substrates are divided among VFA, gas and microbial biomass, thus the lower gas production was explained by greater VFA and microbial mass production with MU35. Lack of the treatment effect on $\mathrm{CH}_{4}$ concentration and production could be due to the same forage to concentrate ratios among diets. Fermentation of forage usually generates more $\mathrm{CH}_{4}$ compared with that of concentrate [35].

\section{Effects of SRU on fermentation characteristics}

Fermenter $\mathrm{pH}$ (averaged 6.80) was much higher than the rumen $\mathrm{pH}$ commonly reported in lactating dairy cow; the high $\mathrm{pH}$ was due to well buffered media by continuous buffer infusion with relative small amount of substrate incubated $(10 \mathrm{~g} / \mathrm{d})$ ). Although increasing the addition of SRU quadratically changed the molar proportion of propionate, BCVFA, valerate and caproate, their differences among treatments were quantitatively minor. The linearly increased the ratio of acetate to propionate with increasing SRU suggests that the fermentation pattern switched to more acetate production. However, the increased the ratio of acetate to propionate was primarily resulted from a linear reduction of propionate proportion rather than increased acetate production, that is consistent with the lack of difference in NDF digestibility. The effects of dietary supplementation of SRU on rumen VFA concentration and individual VFA profiles in literature are inconsistent; for example, no difference in total or individual VFA concentrations in Rustitec [7], a decrease in the molar proportion of acetate [36], whereas an increase in the production of acetate were reported [9]. It suggests that the influence of SRU on rumen VFA production vary with diet, dose of $\mathrm{SRU}$, and the methodology. 
The lower fermenter $\mathrm{pH}$ with MU35 than control is consistent with the higher total VFA concentration and greater $\mathrm{OM}$ digestibility. The greater ratio of acetate to propionate with MU35 than control is the result of its numerically higher NDF digestibility. A high acetate to propionate ratio is an indication of proportionally higher digestible NDF in the feeds. Additionally, the higher BCVFA proportion in MU35 group can be explained the increased protein degradation. Formation of BCVFA occurs during protein degradation due to branched chain amino acid deamination [37].

\section{Effects of SRU on microbial protein synthesis and microbial community}

Ruminal microbial protein synthesis is primarily driven by ruminal availability of energy and protein. The greater total microbial protein production with MU35 than control was resulted from numerically increased FPB and LAB fractions, and it is accordance with the higher OM digestibility. However, the quadratically increased microbial protein synthesis with increasing SRU addition from $0,0.28-0.56 \%$ was not supported by the OM digestibility, which was not different among the three doses of SRU. Whereas, the linearly increased ammonia $\mathrm{N}$ concentration with increasing SRU addition may be beneficial to microbial protein production in the present study. Xin et al. [7] measured in vitro rumen ammonia $\mathrm{N}$ release dynamics, and suggested that adding SRU in dairy cow diets would prolong microbial utilization of additional $\mathrm{N}$ sources during ruminal fermentation. Therefore, improve the synchronization between ruminal $\mathrm{NH}_{3}-\mathrm{N}$ release and carbohydrate availability, consequently result in greater microbial protein synthesis. The results observed from studies using beef steers $[29,38]$ support the suggestion that addition of SRU made a greater synchronization of fermentable carbohydrates and $\mathrm{N}$ in rumen.

Rumen microbial diversity and community composition based on next generation sequencing were affected by adding SRU in yak diet [39]. However, in the present study, the microbial community observed as OTUs or Shannon diversity index in both FPA and LAB samples only numerically increased with SRU supplementation compared to control because of substantial individual variation. Similarly, the results of the NMDS indicated no specific clustering of microbial community from both FPA and LAB fractions. In contrast, a study on rumen bacteria of finishing bull found that low level of urea (0.8\%) addition had a higher Shannon index and observed OTUs than high level of urea group (2\%). This discrepancy may be caused by the low dose of SRU in the current study (max. $0.56 \%$ ). In fact, the supplementation rate of SRU was 1 and $2 \%$, respectively, for the low and high levels added to yak diet in the study of Yan et al. [8], of which the diversity index (Shannon index) for the low SRU group was higher than that for the high SRU group. It suggests that the impact of SRU addition on rumen microbial community is a dose-dependent. Spanghero et al. [34] reported that the high ammonia N concentration can inhibit rumen bacterial growth. The SRU reduced ammonia $\mathrm{N}$ concentration through the inhibition of the hyper-ammonia-producing bacteria, a small group of ruminal bacteria that are responsible for the most of the $\mathrm{NH}_{3}-\mathrm{N}$ production [10]

Firmicutes and Bacteroidetes were the top 2 phyla, which was consistent with the results of previous study on rumen of Yak [8], beef cattle [39], and bull [1]. The greater RA of Firmicutes with MU35 than control in LAB samples is consistent with the increased digestibility of OM, VFA production and microbial 
protein synthesis. Min et al. [40] reported that a higher phylum Firmicutes populations was related to lower $A: P$ ratio and higher $A D G$, and the authors suggested that the great abundance of Firmicutes within the rumen may play a role in improving feed efficiency. Additionally, the MU35 reduced the RA of Succinivibrio from phyla Proteobacteria compared with control. The RA of Succinivibrio was positively correlated with butyrate and valerate, indicating Succinivibrio was a main contributor for higher concentrations of butyrate and valerate [41]. This would explain the lower concentration of butyrate with MU35 group than control.

The enhanced genus of Family XIII AD3011 from phyla Firmicutes in U56 and MU35 indicated its susceptible to SRU supplementation in LAB samples. The information and function of genus Family XIII AD3011 group in the rumen is limited. Methanobrevibacter is able to use hydrogen and carbon dioxide, and format as substrates for methane production. Our results showed that the RA of Methanobrevibacter from phylum Euryarchaeota was lower with U56 than control for LAB fraction, which is consistent with quadratic change of $\mathrm{CH}_{4}$ production, expressed as $\mathrm{mg} / \mathrm{d}$ or $\mathrm{mg} / \mathrm{g}$ digested DM.

\section{Conclusion}

Increasing supplementation of dairy cow diet with SRU from $0,0.28-0.56 \%$ in DM basis linearly increased fermenter $\mathrm{NH}_{3}-\mathrm{N}$ concentration, ratio of acetate to propionate and microbial protein efficiency without affecting nutrient digestibility in RUSITEC. These results suggested that maintaining high $\mathrm{NH}_{3}-\mathrm{N}$ concentration due to adding SRU may improve the synchronization between ruminal $\mathrm{NH}_{3}-\mathrm{N}$ release and carbohydrate availability, consequently result in increase of microbial protein synthesis. Adding SRU along with slightly higher available energy by adding corn grain increased nutrient digestibility, microbial protein synthesis, and decreased gas production. It suggested that increased high fermentable energy such as steam flaked corn may further improve beneficial effect of SRU on the rumen fermentation. Although the small amount of SRU was added in an in vitro fermentation system, the results demonstrated the potential benefits to add the SRU for improving ruminal digestibility and microbial protein synthesis. An in vivo study using dairy cows is warranted to better explore the beneficial impact of SRU.

\section{Abbreviations}

$A: P$, Ratio of acetate to propionate; ADF, Acid detergent fibre; BCVFA: Branched-chain volatile fatty acids (isobutyrate + isovalerate); CP: Crude protein; DM: Dry matter; FPA: Feed particle associated bacteria; FPB: Feed particle-bound bacteria; LAB: Liquid associated bacteria; NDF: Neutral detergent fibre; NMDS: Nonmetric multidimensional scaling; NPN: Non-protein nitrogen; OM: Organic matter; RA: Relative abundance; RUSITEC: Rumen simulation technique; SBM: Soybean meal; SRU: Slow-release urea; TMR: Total mixed ration; VFA: Volatile fatty acid;

\section{Declarations}


Acknowledgements

Feeds and slow-release urea were provided by King Techina Feed Co., Ltd., (Hangzhou, China). The authors thank A. Furtado (sampling and laboratory analysis), and D. Vedres (chromatography). We also thank the barn staff of the Lethbridge Research and Development Centre for the care and management of the beef cows.

\section{Authors' contributions}

WZY, YMG designed the study and revised manuscript; SMY, DYN and LX revised manuscript; LJ analyzed microbial data and revised manuscript; YMG performed this study, analyzed the data and wrote the manuscript. All authors read and approved the final manuscript.

\section{Funding}

This work was financially supported by the Alberta Agriculture and Forestry (\#2015E006R) and King Techina Feed Co., Ltd. (Hangzhou, China).

\section{Availability of data and materials}

The data analyzed during the current study are available from the corresponding author on reasonable request.

\section{Ethics approval and consent to participate}

All the procedures for the treatment and care of experimental cattle were approved by the Animal Care and Use Committee of Lethbridge Research and Development Centre and followed the guidelines of the Canadian Council on Animal Care (2009).

\section{Consent for publication}

Not applicable.

\section{Competing interests}

The authors declare that they do not have any conflict of interest.

\section{Author details}

${ }^{1}$ Inner Mongolia Key Laboratory of Animal Nutrition and Feed Science, College of Animal Science, Inner Mongolia Agricultural University, Hohhot, 010018, Inner Mongolia, China.

${ }^{2}$ Agriculture and Agri-Food of Canada, Lethbridge Research and Development Centre, Lethbridge, $A B, T 1 \mathrm{~J}$ 4B1, Canada. ${ }^{3}$ Hangzhou King Techina Feed Co., Ltd, Hangzhou, China. ${ }^{4}$ College of Veterinary Medicine, University of Calgary, 2500 University Dr. NW, Calgary, AB, T2N 1N4, Canada. 


\section{References}

1. Zhou Z, Meng Q, Li S, Jiang L, Wu H. Effect of urea-supplemented diets on the ruminal bacterial and archaeal community composition of finishing bulls. Appl Microbiol Biotechnol. 2017; 101:62056216.

2. Satter LD, Roffler RE. Nitrogen requirement and utilization in dairy cattle. J Dairy Sci. 1975;58(8):1219-1237.

3. Cherdthong A, Wanapat M. Development of Urea Products as Rumen Slow-Release Feed for Ruminant Production: A Review. Aust Journal of Basic \& Appl Sci. 2010;4(8):2232-2241.

4. Taylor-Edwards CC, Elam NA, Kitts SE, McLeod KR, Axe DE, Vanzant ES, et al. Influence of slowrelease urea on nitrogen balance and portal-drained visceral nutrient flux in beef steers. J Anim Sci. 2009;(1):209-221.

5. Tedeschi LO, Baker MJ, Ketchen DJ, Fox DG. Performance of growing and finishing cattle supplemented with a slow-release urea product and urea. Can J Anim Sci. 2002;82(4):567-573.

6. Galo E, Emanuele SM, Sniffen CJ, White JH, Knapp JR. Effects of a polymer-coated urea product on nitrogen metabolism in lactating Holstein dairy cattle. J Dairy Sci. 2003;86:2154-2162.

7. Xin HS, Schaefer DM, Liu QP, Axe DE, Meng QX. Effects of polyurethane coated urea supplement on in vitro ruminal fermentation, ammonia release dynamics and lactating performance of Holstein dairy cows fed a steam-flaked corn-based diet. Asian Austral J Anim. 2010;23(23):491-500.

8. Yan XT, Yan BY, Ren QM, Dou JJ, Wang WW, Zhang JJ, et al. Effect of slow-release urea on the composition of ruminal bacteria and fungi communities in yak. Anim Feed Sci Tech. 2018;244:S0377840118306679.

9. Alipour D, Saleem AM, Sanderson H, Brand T, Santos LV, Mahmoudi-Abyane M, et al. Effect of combinations of feed-grade urea and slow-release urea in a finishing beef diet on fermentation in an artificial rumen system. Transl Anim Sci. 2020;4:839-847.

10. Ferme D, Banjac M, Calsamiglia S, Busquet M, Kamel C, Avguštin G. The effects of plant extracts on microbial community structure in a rumen-simulating continuous-culture system as revealed by molecular profiling. Folia Microbiol. 2004;49(2):151-155.

11. Chalupa W. Precision feeding of nitrogen to lactating dairy cows: a role for Optigen ${ }^{\circledR}$ II. Nutritional biotechnology in the feed and food industries. Proc. Alltech's 23rd Annu. Symp. Lexington, KY, USA. 2007;pp:221.

12. Wanapat M, Polyorach S, Boonnop K, Mapato C, Cherdthonget A. Effects of treating rice straw with urea or urea and calcium hydroxide upon intake, digestibility, rumen fermentation and milk yield of dairy cows. Livest Sci. 2009;125(2):238-243.

13. Canadian Council on Animal Care (CCAC). Guide to the care and use of farm animals in research, teaching and testing. Ottawa: CCAC; 2009.

14. Czerkawski JW, Breckenridge G. Design and development of a long-term rumen simulation technique (Rusitec). Br J Nutr. 1977;38:371-84 
15. McDougall El. Studies on ruminant saliva. 1. The composition and output of sheep's saliva. Biochem J. 1948;43:99-109.

16. Saleem AM, Jr GOR, Yang WZ, Ran T, McAllister TA. Effect of engineered biocarbon on rumen fermentation, microbial protein synthesis, and methane production in an artificial rumen (RUSITEC) fed a high forage diet. J Anim Sci. 2018;96(8):3121-3130.

17. Association of Official Analytical Chemists International. Official Methods of Analysis, 18th ed. AOAC International, Gaithersburg, MD.2005.

18. Van Soest PJ, Robertson JB, Lewis BA. Methods for dietary fiber, neutral detergent fiber, and nonstarch polysaccharides in relation to animal nutrition. J Dairy Sci. 1991;74(10):3583-3597.

19. Smith KA, Tabatabai MA. Automated Instruments for the Determinayion of Total Carbon, Hydrogen, Nitrogen, Sulfur, and Oxygen. In Soil and environmental analysis: Modern instrument techniques, Cresser. New York: Marcel Dekker. 2004.

20. Rode LM, Yang WZ, Beauchemin KA. Fibrolytic enzyme supplements for dairy cows in early lactation. J Dairy Sci. 1999;82(10):2121-2126.

21. Rhine ED, Mulvaney RL, Pratt EJ, Sims GK. Improving the Berthelot reaction for determining ammonium in soil extracts and water. Soil Sci Soc Am J. 1998;62:473-480.

22. Walters W, Hyde ER, Berg-Lyons D, Ackermann G, Humphrey G, Parada A, et al. Improved Bacterial 16S rRNA Gene (V4 and V4-5) and Fungal Internal Transcribed Spacer Marker Gene Primers for Microbial Community Surveys. Msystems. 2016;1(1):e00009-15.

23. Ewels $P$, Magnusson M, Lundin S, Käller M. MultiQC: summarize analysis results for multiple tools and samples in a single report. Bioinformatics. 2016;(19):3047-3048.

24. Bolyen E, Rideout JR, Dillon MR, Bokulich AN, Abnet CC, Al-Ghalith GA, et al. Reproducible, interactive, scalable and extensible microbiome data science using QIIME 2. Nat Biotechnol. 2019;37:852-7.

25. Oksanen J, Guillaume BF, Kindt R, Legendre P, Minchin P, O'Hara R, et al. Vegan: community ecology package. R package Version 2.4-4. 2017.

26. McMurdie PJ, Holmes S, Watson M. phyloseq: a R package for reproducible interactive analysis and graphics of microbiome census data. PLoS One. 2013;8(4):e61217.

27. Love MI, Huber W, Anders S. Moderated estimation of fold change and dispersion for RNA-seq data with DESeq2. Genome Biol. 2014;15:550.

28. Calomeni GD, Gardinal R, Venturelli BC, Freitas Júnior JED, Vendramini T, Takiya CS, et al. Effects of polymer-coated slow-release urea on performance, ruminal fermentation, and blood metabolites in dairy cows. R Bras Zootec. 2015;44(9):327-334.

29. Gardinal R, Calomeni GD, Cônsolo NR, Takiya CS, Freitas JE Jr, Gandra JR, et al. Influence of polymercoated slow-release urea on total tract apparent digestibility, ruminal fermentation and performance of Nellore steers. Asian Austral J Anim, 2017;30(1):34-41.

30. Galinaa MA, F Pe'Rez-Gild, Ortizc R, Hummel JD, Ørskov RE. Effect of slow release urea supplementation on fattening of steers fed sugar cane tops (Saccharum officinarum) and maize 
(Zea mays): ruminal fermentation, feed intake and digestibility. Livest Prod Sci. 2003;83:1-11.

31. Mehrez AZ, Orskov ER, McDonald I. Rates of rumen fermentation in relation to ammonia concentration. Br J Nutr. 1977;38(3):437-443.

32. Leng RA, Nolan JV. Nitrogen metabolism in the rumen. J Dairy Sci. 1984;67(5):1072-1089.

33. Bryant MP. Nutritional requirements of the predominant rumen cellulolytic bacteria. Fed Proc. 1973;32:1809-1813.

34. Spanghero M, Nikulina A, Mason F. Use of an in vitro gas production procedure to evaluate rumen slow-release urea products. Anim. Feed Sci Technol. 2018;237:19-26.

35. Aguerre MJ, Wattiaux MA, Powell JM, Broderick GA, Arndt C. Effect of forage-to-concentrate ratio in dairy cow diets on emission of methane, carbon dioxide, and ammonia, lactation performance, and manure excretion. J Dairy Sci. 2011;94(6):3081-3093.

36. Matthews AK, Poore MH, Huntington GB, Green JT. Intake, digestion, and N metabolism in steers fed endophyte-free, ergot alkaloid-producing endophyte-infected, or nonergot alkaloid-producing endophyte-infected fescue hay. J Anim Sci. 2005;83(5):1179-1185.

37. Tedeschi LO, Fox DG, Russell JB. Accounting for ruminal deficiencies of nitrogen and branched-chain amino acids in the structure of the Cornell net carbohydrate and protein system. Proceedings of Cornell Nutrition Conference for Feed Manufacturers; New York: Cornell University; 2000.

38. Almora E, Huntington GB, Burns JC. Effects of supplemental urea sources and feeding frequency on ruminal fermentation, fiber digestion, and nitrogen balance in beef steers. Anim Feed Sci Tech. 2012;171(2-4):136-145.

39. Ran T, Jin L, Abeynayake R, Saleem AM, Zhang X, Niu D, et al. Effects of brewers' spent grain protein hydrolysates on gas production, ruminal fermentation characteristics, microbial protein synthesis and microbial community in an artificial rumen fed a high grain diet. J Anim Sci Biotechno. 2021;12(1):1.

40. Min BR, Gurung N, Shange R, Solaiman S. Potential role of rumen microbiota in altering average daily gain and feed efficiency in meat goats fed simple and mixed pastures using bacterial tag-encoded FLX amplicon pyrosequencing1. J Anim Sci. 2019;97(8):3523-3534.

41. Xue MY, Sun HZ, Wu XH, Guan LL, Liu JX. Assessment of rumen bacteria in dairy cows with varied milk protein yield. J Dairy Sci, 2019; 102(6):5031-5041.

\section{Figures}




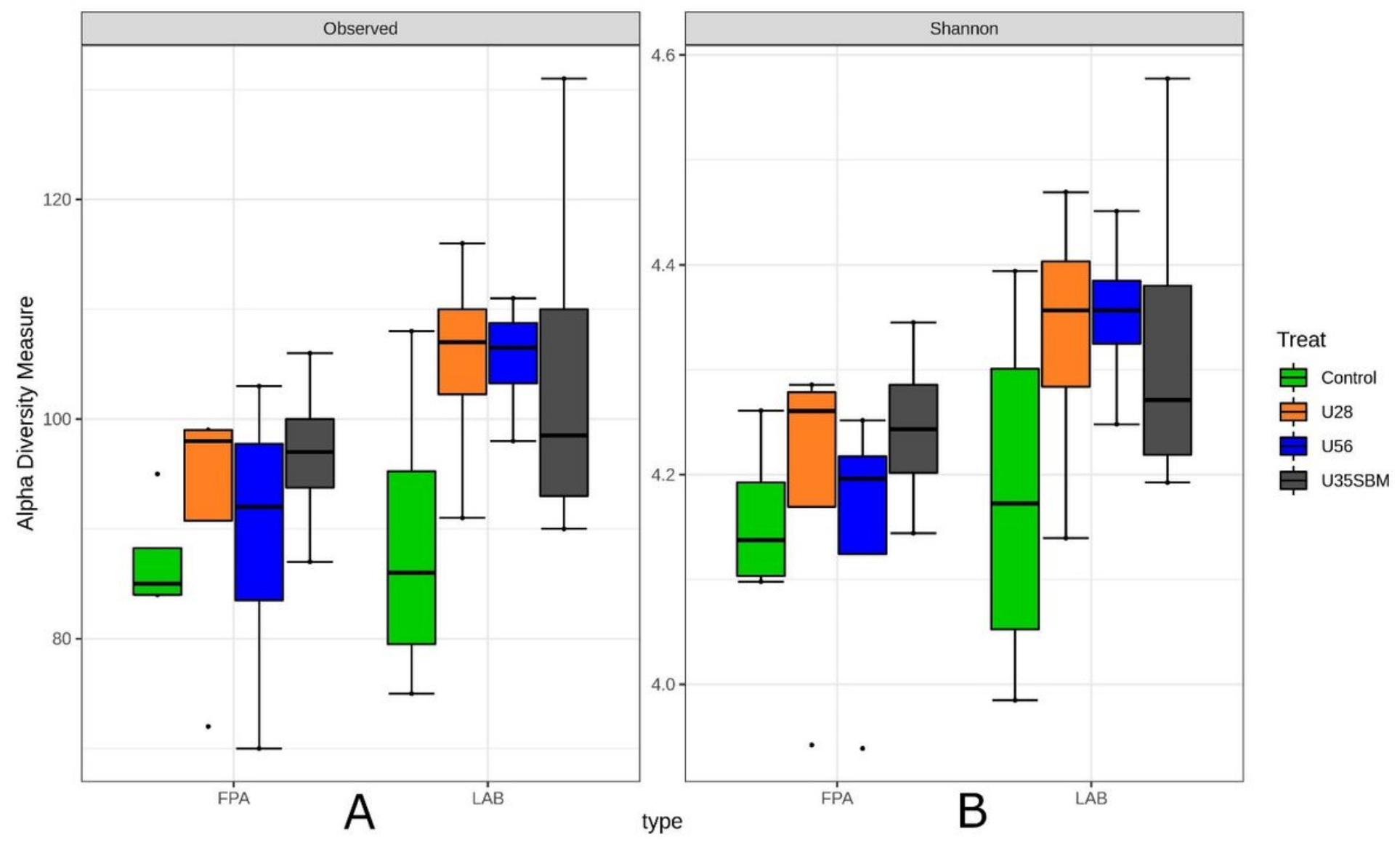

Figure 1

Box plots of the (A) observed OTUs and (B) Shannon diversity index for feed particle-associated (FPA, left) and liquid-associated bacteria ( $L A B$, right) samples by treatment. Treatments were: control diet (no $\mathrm{SRU}), \mathrm{U} 28$ = control plus $0.28 \% \mathrm{SRU}, \mathrm{U} 56$ = control plus $0.56 \% \mathrm{SRU}$, and MU35 = control diet was modified by partially replacing soybean protein with $0.35 \%$ SRU (DM basis). Different lowercase letters within each sampling time represent different means $(P<0.05)$. Error bars indicate \pm standard error of the mean. The box in the plots indicates the interquartile range (IQR) (middle $50 \%$ of the data), the middle line represents the median value, and the whiskers represents 1.5 times the IQR. 


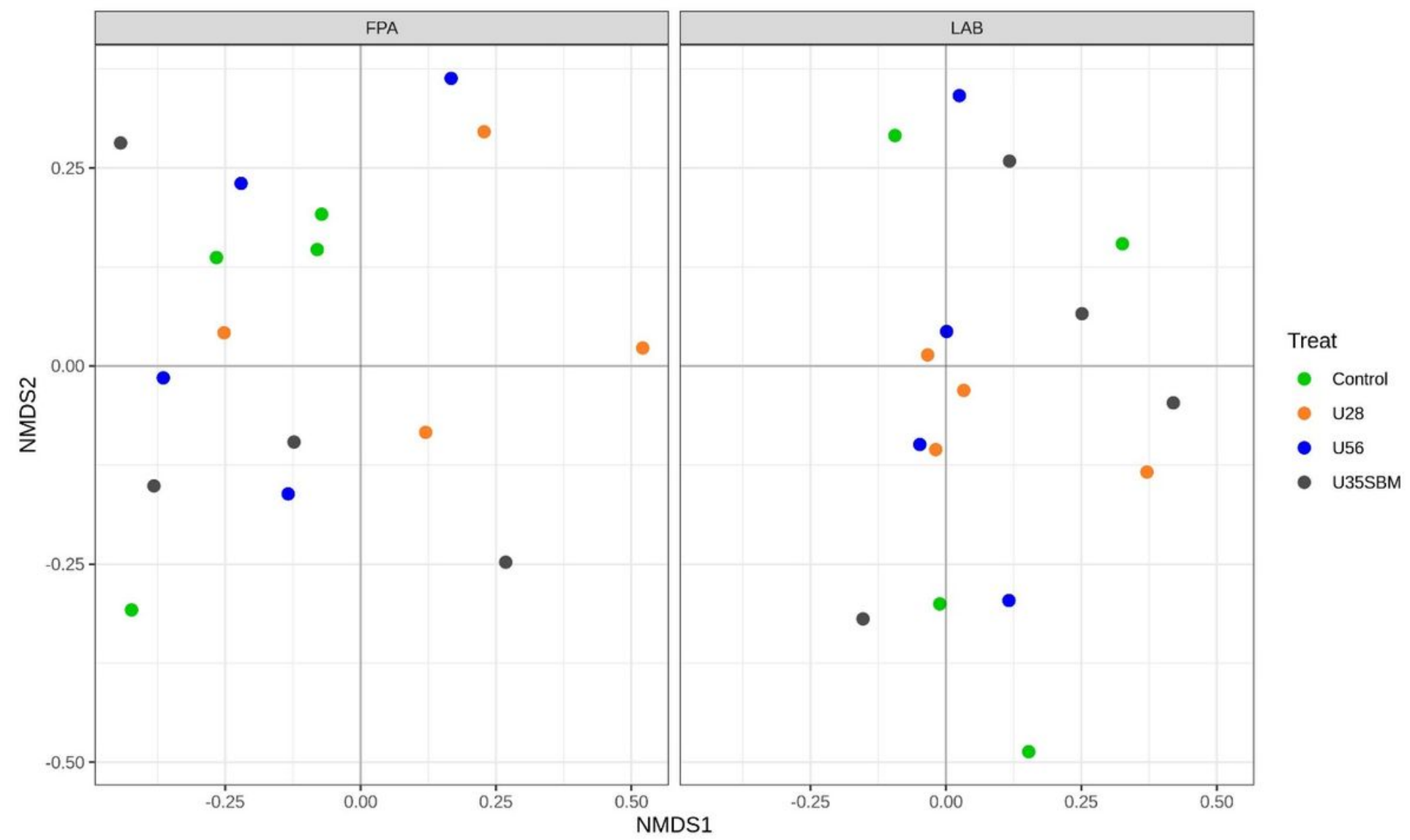

Figure 2

Non-metric multidimensional scaling (NMDS) plots of the Bray-Curtis dissimilarities for feed particleassociated (FPA, left) and liquid-associated bacteria ( $L A B$, right) samples by treatment. Treatments were: control diet (no SRU), U28 = control plus $0.28 \%$ SRU, U56 = control plus $0.56 \%$ SRU, and MU35 = control diet was modified by partially replacing soybean protein with $0.35 \%$ SRU (DM basis). 


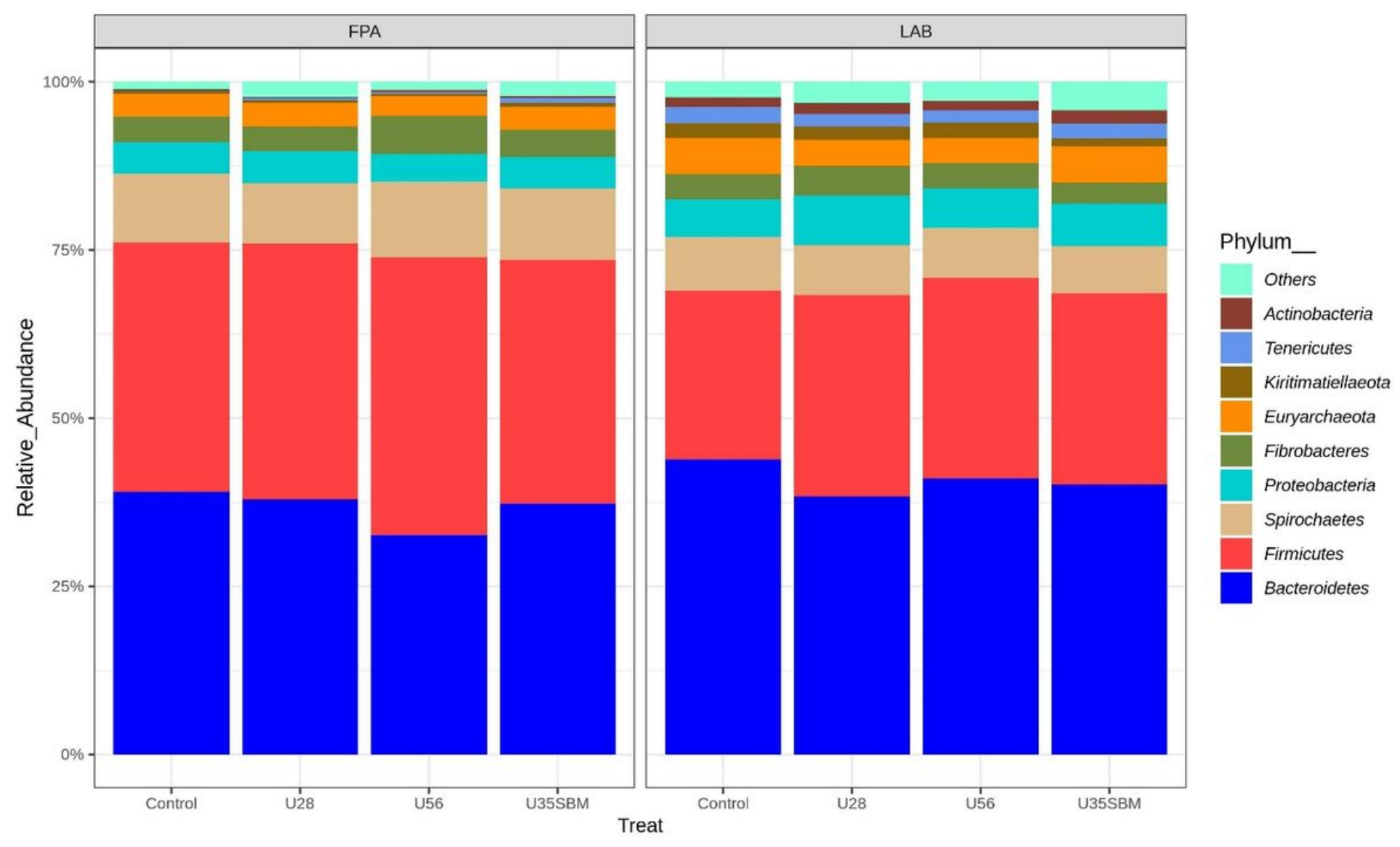

Figure 3

Effects of slow-release urea (SRU) on the relative abundance of ruminal microbial at phylum level for feed particle-associated (FPA, left) and liquid-associated bacteria (LAB, right) samples. Treatments were: control diet (no SRU), U28 = control plus $0.28 \%$ SRU, U56 = control plus $0.56 \%$ SRU, and MU35 = control diet was modified by partially replacing soybean protein with $0.35 \%$ SRU (DM basis). 

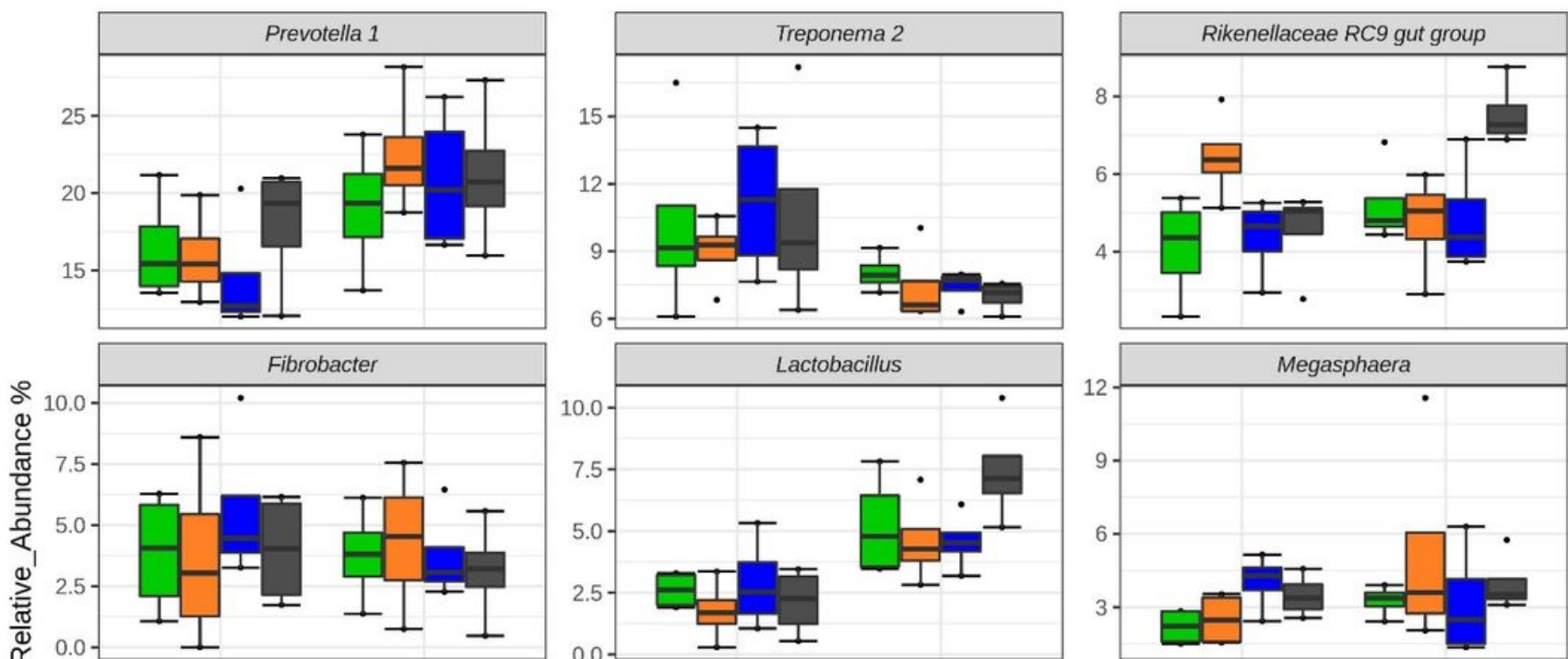

Treat
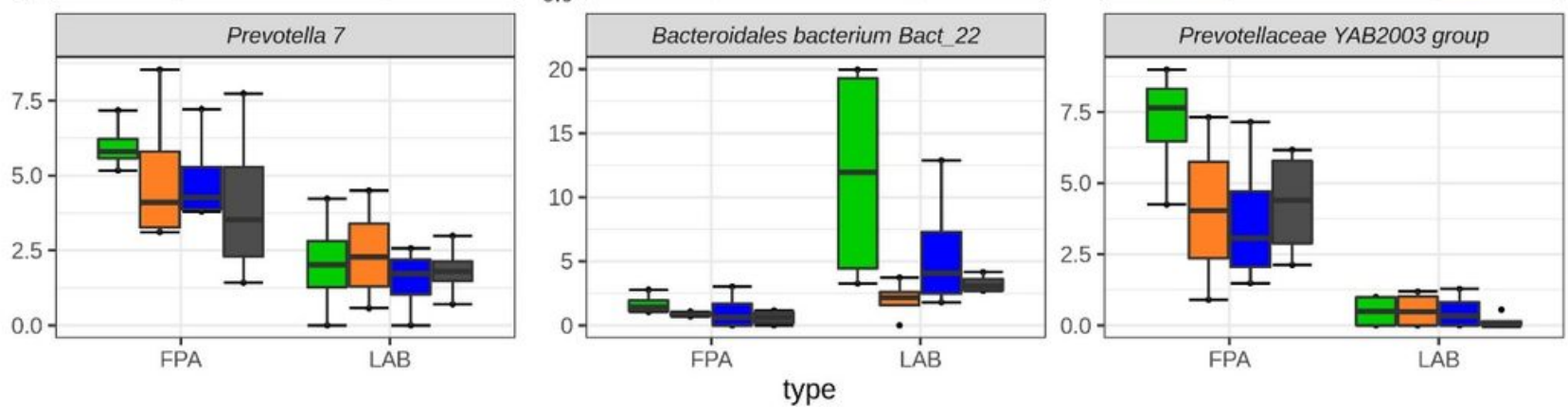

Figure 4

Relative abundance of the 9 most abundant genus in the microbiota of FPA and LAB samples by treatment. Treatments were: control diet (no SRU), U28 = control plus $0.28 \% \mathrm{SRU}$, U56 = control plus $0.56 \% \mathrm{SRU}$, and MU35 = control diet was modified by partially replacing soybean protein with $0.35 \% \mathrm{SRU}$ (DM basis). 


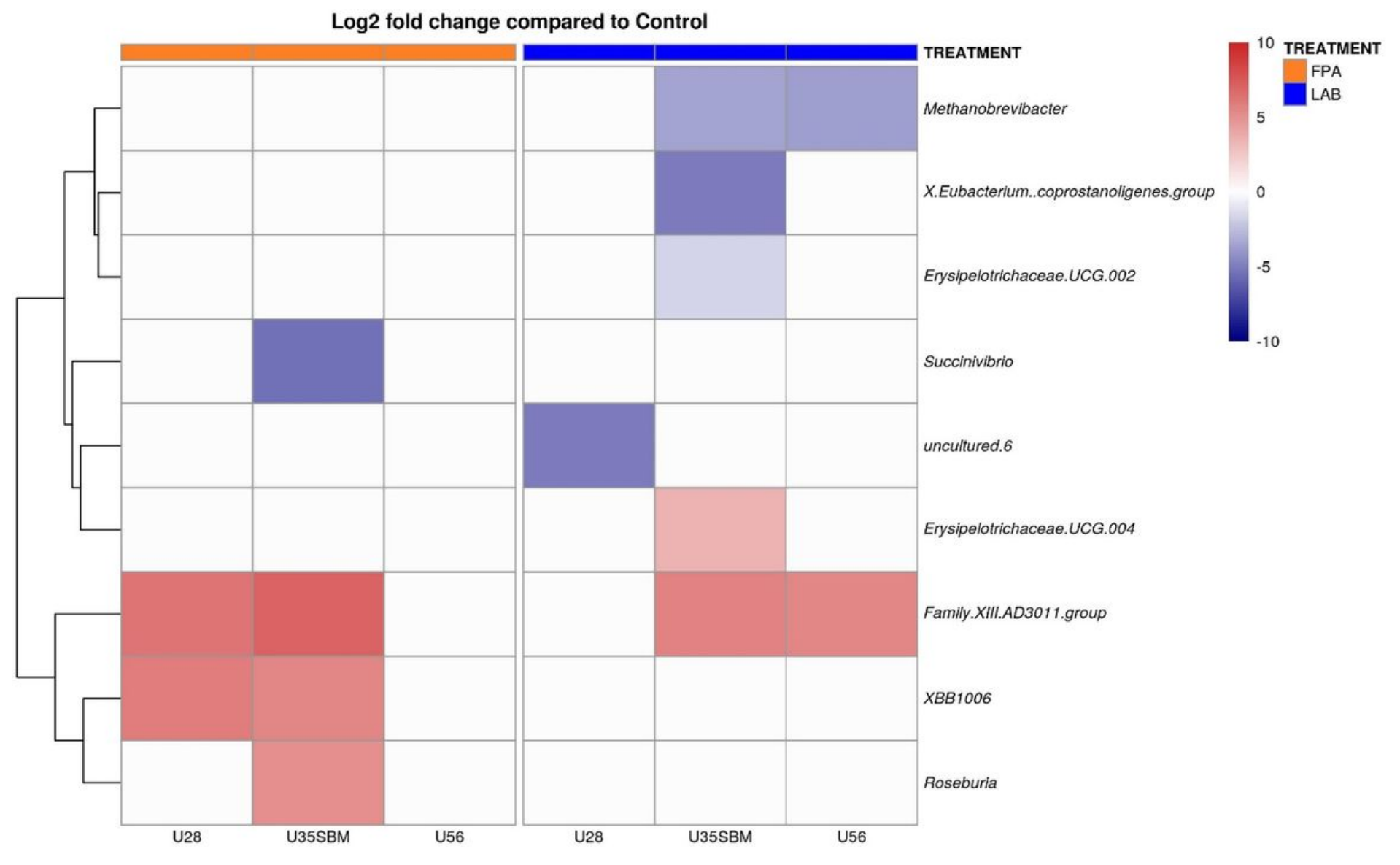

Figure 5

Relative changes (log2 fold; Padj < 0.05 ) of ruminal bacterial by treatment vs. control (CON) at genus level, orange for feed particle-associated (FPA, left) samples and blue for liquid-associated bacteria (LAB, right) samples. Treatments were: control diet (no SRU), U28 = control plus $0.28 \%$ SRU, U56 = control plus $0.56 \% \mathrm{SRU}$, and MU35 = control diet was modified by partially replacing soybean protein with $0.35 \% \mathrm{SRU}$ (DM basis). 